\title{
EFEKTIFITAS SISTEM RBC PADA IPAL PEKAPURAN RAYA PD.PAL BANJARMASIN TERHADAP PENURUNAN KADAR BOD
}

\author{
Fidyan Hifzhani., Syarifudin A., Arifin \\ Poltekkes Kemenkes Banjarmasin Jurusan Kesehatan Lingkungan \\ Jl. H. Mistar Cokrokusumo No.1A Banjarbaru Kalimantan Selatan 70714 \\ E-mail: sarkininasroem@gmail.com
}

\begin{abstract}
Effectiveness Of Rbc System On Wwtp (Wastewater Treatment Plant) Pekapuran Raya Wt (Wastewater Treatment) Local Company Banjarmasin To Reduce Bod Contents. Increased household activities lead to increase the volume of waste generated over time. Annually, the household waste volume increases 5 million m3. WT Local Company Banjarmasin is a wastewater management company that performs domestic sewage treatment (feces) Banjarmasin city. Application of waste treatment technology on WWTP Banjarmasin is RBC system. This study aimed to determine the effectiveness of RBC system on WT Local Company Banjarmasin to reduce BOD (Biological Oxygen Demand). This type of study was analytic. The study design used one group pretest posttest design. The place of study was WWTP Pekapuran Raya WT Local Company Banjarmasin 2017. The study population was wastewater from inlet and outlet pipes. Sample was wastewater taken inlet and outlet pipe tanks. The result showed BOD (Biological Oxygen Demand) contents in the wastewater sample before it was processed of $130.97 \mathrm{mg} / \mathrm{L}, 116.98 \mathrm{mg} / \mathrm{L}$, and 193.45 $\mathrm{mg} / \mathrm{l}$. After it was processed of $13.81 \mathrm{mg} / \mathrm{L}, 20.138 \mathrm{mg} / \mathrm{L}$, and $30.216 \mathrm{mg} / \mathrm{L}$. The effectiveness of RBC system on the reduce of BOD (Biological Oxygen Demand) in WWTP Pekapuran Raya WT Local Company Banjarmasin was $89.37 \%$ for first day, $80.51 \%$ for second day and $83.73 \%$ for the third day. There were differences before and after BOD (Biological Oxygen Demand) treated by RBC in WWTP Pekapuran Raya WT Local Company Banjarmasin.
\end{abstract}

Keywords: WWTP; RBC system; BOD.

\begin{abstract}
Abstrak: Efektifitas Sistem RBC Pada IPAL Pekapuran Raya PD PAL Banjarmasin Terhadap Penurunan Kadar BOD. Meningkatnya aktivitas manusia di rumah tangga menyebabkan semakin besarnya volume limbah yang dihasilkan dari waktu ke waktu. Volume limbah rumah tangga meningkat 5 juta $\mathrm{m}^{3}$ pertahun. PD PAL Kota Banjarmasin adalah perusahaan daerah pengelola air limbah kota Banjarmasin yang melakukan pengolahan air limbah sektor domestik (tinja) kota Banjarmasin. Teknologi pengolahan limbah yang diterapkan pada IPAL Kota Banjarmasin adalah sistem RBC. Penelitian ini bertujuan untuk mengetahui efektivitas sistem RBC pada PD PAL Banjarmasin terhadap penurunan kadar BOD (Biological Oxygen Demand). Jenis penelitian ini bersifat analitik. Desain penelitian yang digunakan adalah one group pretest posttest design. Tempat pelaksanaan penelitian dilakukan di IPAL Pekapuran Raya PD PAL Kota Banjarmasin Tahun 2017. Populasi penelitian adalah limbah cair dari pipa inlet dan outlet. Sampel adalah air limbah yang diambil dalam bak penampung pipa inlet dan outlet. Hasil penelitian menunjukan Kadar BOD (Biological Oxygen Demand) pada sampel air limbah sebelum diolah $130,97 \mathrm{mg} / \mathrm{l}, 116,98 \mathrm{mg} / \mathrm{l}$, dan 193,45 mg/l. Sesudah dilakukan pengolahan 13,81 mg/l, 20,138 mg/l, dan 30,216 mg/l. Efektifitas RBC terhadap penurunan kadar BOD (Biological Oxygen Demand) pada IPAL Pekapuran Raya PD PAL kota Banjarmasin adalah dengan ratarata $89,37 \%$ untuk hari pertama, $80,51 \%$ untuk hari kedua, dan $83,73 \%$ untuk hari ketiga. Terdapat perbedaan kadar BOD (Biological Oxygen Demand) sebelum dan sesudah diolah dengan RBC pada IPAL Pekapuran Raya PD PAL kota Banjarmasin.
\end{abstract}

Kata kunci: IPAL; Sistem RBC; BOD. 


\section{PENDAHULUAN}

Meningkatnya aktivitas manusia di rumah tangga menyebabkan semakin besarnya volume limbah yang dihasilkan dari waktu ke waktu. Keadaan tersebut menyebabkan terjadinya pencemaran yang banyak menimbulkan kerugian bagi manusia dan lingkungan [1]. Sumber penghasil limbah cair terbesar di negara ini adalah dari hasil aktivitas rumah tangga. Hal ini dikarenakan jumlah penduduk di Indonesia yang sangat besar. Oleh karena itu volume limbah domestik yang dihasilkan juga besar [2]. Semakin banyaknya air yang tercemar akibat adanya aktifitas manusia maka akan terjadi kerusakan lingkungan sehingga menurunnya tingkat kesehatan manusia yang tinggal pada lingkungannya itu sendiri. Oleh karena itu perlu dilakukan penanganan air limbah yang seksama dan terpadu baik itu dalam penyaluran maupun pengolahannya [3].

PD PAL Kota Banjarmasin adalah perusahaan daerah pengelola air limbah kota Banjarmasin yang berfungsi melakukan pengolahan air limbah sektor domestik (tinja) kota Banjarmasin sesuai tugas dan fungsi yang di atur dalam PERDA Kota Banjarmasin. Teknologi pengolahan air limbah yang diterapkan pada IPAL Kota Banjarmasin secara keseluruhan adalah Reaktor Rotating Biological Contactor (RBC) yaitu sistem pengolahan biologi tipe fixed film yang menggunakan media plastik berputar dengan cara mengontakkan air limbah dengan media tersebut sehingga penangkapan udara oleh air menyebabkan oksigen terlarut (DO) menjadi bertambah yang akan dimanfaatkan oleh mikroorganisme dalam menguraikan zat-zat tertentu terutama BOD dan COD [3].

Penting sekali dilakukan penilaian keefektifan dari alat RBC agar hasil akhir dari pengolahan limbah cair domestik yang ada di PD. PAL khususnya di IPAL Pekapuran Raya Banjarmasin aman untuk di buang kelingkungan dan tidak mencemari lingkungan. Berdasarkan data yang didapat pada pemeriksaan di pipa inlet pada bulan November tahun 2016 terdapat parameter yang belum memenuhi persyaratan seperti bakteri E.coli mencapai $140.000 \mathrm{mg} / \mathrm{l}$ dan BOD $344,76 \mathrm{mg} / \mathrm{l}$. Adapun beberapa kelemahan dari proses pengolahan air limbah dengan sistem RBC antara lain yakni pengontrolan jumlah mikroorganisme sulit dilakukan, sensitif terhadap perubahan temperatur dan terkadang konsentrasi BOD air olahan masih tinggi [4].

\section{BAHAN DAN CARA PENELITIAN}

Pada penelitian ini yang digunakan bersifat analitik yaitu untuk mengetahui efektifitas sistem RBC pada IPAL Pekapuran Raya PD. PAL Banjarmasin terhadap penurunan Kadar BOD (Biological Oxygen Demand) Tahun 2017. Desain atau rancang bangun penelitian yang digunakan adalah one group pretest posttest design yaitu penelitian yang menggunakan hubungan sebab akibat dengan cara melibatkan satu kelompok subyek [5]. Penelitian ini dilakukan di PD.PAL Banjarmasin yang beralamat di Pekapuran Raya. Penelitian ini dilakukan pada bulan Februari sampai dengan Juni tahun 2017. Pengulangan yang dilakukan dalam penelitaian ini adalah sebanyak 3 (tiga) kali dimana mewakili 3 waktu pagi (09.00 WITA), siang (12.00 WITA) dan malam (21.00 WITA). Dalam analisis data akan digunakan Paired sample $T$ test. Paired sample $T$ test merupakan uji beda dua sampel berpasangan. Sampel berpasangan merupakan subjek yang sama namun mengalami perlakuan yang berbeda.

\section{HASIL PENELITIAN DAN PEMBAHASAN}

Perusahaan Daerah Pengelola Air Limbah (PD PAL) Kota Banjarmasin berlokasi di Jalan Pasar Pagi No. 89. Perusahaan tersebut merupakan Perusahaan Daerah milik Pemerintah Kota Banjarmasin yang betugas sebagai pengelola air limbah permukiman atau air limbah domestik di Kota Banjarmasin. PD PAL Kota Banjarmasin menggunakan teknologi pengelohan air limbah adalah 
Rotation Biological Contactor (RBC) yaitu system pengelohan biologi tipe fixed film yang menggunakan media plastic berputar. PD PAL Kota Banjarmasin menggunakan dua system yaitu; system off site dan on site (layanan mobile). Sistem off site ialah sambungan rumah ke PD PAL sedangkan on site ialah pengambilan limbah dengan menggunakan mobil penyedot. Waktu tinggal limbah di RBC ialah 1-2 jam, sedangkan lama waktu limbah dari inlet sampai outlet memerlukan waktu \pm 12 jam [3].

Hasil pengukuran suhu air limbah sebelum dan sesudah pengolahan dapat dilihat pada Tabel 1 sebagai berikut :

Tabel 1. Hasil Pengukuran suhu air limbah sebelum dan sesudah pengolahan

\begin{tabular}{cclcc}
\hline No. & $\begin{array}{c}\text { Hari } \\
\text { Pengambilan } \\
\text { Sampel }\end{array}$ & Waktu & \multicolumn{2}{c}{ Suhu $\left.{ }^{\circ} \mathrm{C}\right)$} \\
Pengukuran & $\begin{array}{c}\text { Sebelum } \\
\text { Pengolahan }\end{array}$ & $\begin{array}{c}\text { Sesudah } \\
\text { Pengolahan }\end{array}$ \\
\hline 1. & I & Pagi & 29 & 28 \\
& & Siang & 28 & 27 \\
& & Malam & 29 & 28 \\
2. & Rata-rata & 28,6 & 27,6 \\
& II & Pagi & 28 & 28 \\
& & Siang & 29 & 28 \\
& & Malam & 29 & 28 \\
3. & III & Rata-rata & 28,6 & 28 \\
& & Pagi & 29 & 27 \\
& & Siang & 30 & 28 \\
& & Malam & 28 & 27 \\
& & Rata-rata & 29 & 27,3 \\
\hline
\end{tabular}

Hasil pengukuran pH air limbah sebelum dan sesudah pengolahan dapat dilihat pada Tabel 2 sebagai berikut:

Tabel 2. Hasil Pengukuran pH air limbah sebelum dan sesudah pengolahan

\begin{tabular}{cclccc}
\hline No. & $\begin{array}{c}\text { Hari } \\
\text { Pengambilan } \\
\text { Sampel }\end{array}$ & $\begin{array}{c}\text { Waktu } \\
\text { Pengukuran }\end{array}$ & $\begin{array}{c}\text { Sebelum } \\
\text { Pengolahan }\end{array}$ & $\begin{array}{c}\text { SH } \\
\text { Pesudah } \\
\text { Pengolahan }\end{array}$ & Baku Mutu* \\
\hline 1. & I & Pagi & 6 & 7 & $6-9$ \\
& & Siang & 6 & 6 & \\
& & Malam & 6 & 7 & \\
2. & Rata-rata & 6 & 6,6 & \\
& II & Pagi & 6 & 7 & \\
& & Siang & 6 & 7 & \\
3. & & Malam & 6 & 6 & \\
& & Rata-rata & 6 & 6,6 & \\
& III & Pagi & 6 & 6 & \\
& & Siang & 6 & 6 & \\
& & Malam & 6 & 7 & \\
\hline
\end{tabular}

*Keterangan : PERGUB Kalimantan Selatan No.4 Tahun 2007 Tentang Bakumutu Limbah Cair

Hasil pemeriksaa $\mathrm{BOD}_{5}$ sebelum dan sesudah pengolahan dapat dilihat pada Tabel 3 sebagai berikut: 
Tabel 3. Hasil Pemeriksaan Kadar $\mathrm{BOD}_{5}$ Pengolahan Air Limbah Sebelum dan Sesudah Pengolahan

\begin{tabular}{|c|c|c|c|c|c|}
\hline \multirow[b]{2}{*}{ No. } & \multirow{2}{*}{$\begin{array}{c}\text { Hari } \\
\text { Pengambilan } \\
\text { Sampel }\end{array}$} & \multirow{2}{*}{$\begin{array}{c}\text { Waktu } \\
\text { Pengukuran }\end{array}$} & \multicolumn{2}{|c|}{ Kadar $\mathrm{BOD}_{5} \mathrm{mg} / \mathrm{l}$} & \multirow[b]{2}{*}{ Baku Mutu* } \\
\hline & & & $\begin{array}{c}\text { Sebelum } \\
\text { Pengolahan }\end{array}$ & $\begin{array}{c}\text { Sesudah } \\
\text { Pengolahan }\end{array}$ & \\
\hline \multirow[t]{4}{*}{1.} & I & Pagi & 126,58 & 16,401 & \\
\hline & & Siang & 132,34 & 10,356 & \\
\hline & & Malam & 132,34 & 14,673 & \\
\hline & & Rata-rata & 130,97 & 13,810 & \\
\hline \multirow[t]{4}{*}{2.} & II & Pagi & 161,12 & 13,839 & \\
\hline & & Siang & 92,22 & 23,273 & \\
\hline & & Malam & 97,60 & 23,304 & \\
\hline & & Rata-rata & 116,98 & 20,138 & \\
\hline \multirow[t]{4}{*}{3.} & III & Pagi & 217,78 & 18,138 & \\
\hline & & Siang & 161,17 & 36,258 & \\
\hline & & Malam & 201,4 & 36,252 & \\
\hline & & Rata-rata & 193,45 & 30,216 & \\
\hline
\end{tabular}

Hasil perhitungan efektivitas sistem RBC dapat dilihat pada tabel 4 sebagai berikut:

Tabel 4. Persentase Efektivitas Pengolahan Air Limbah Sebelum Dan Sesudah Pengolahan

\begin{tabular}{|c|c|c|c|c|}
\hline No. & $\begin{array}{c}\text { Hari } \\
\text { Pengambilan } \\
\text { Sampel }\end{array}$ & $\begin{array}{c}\text { Waktu } \\
\text { Pengukuran }\end{array}$ & $\begin{array}{c}\text { Persentase Efektivitas } \\
\text { Pengolahan } \\
(\%)\end{array}$ & $\begin{array}{c}\text { Rata-rata } \\
(\%)\end{array}$ \\
\hline \multirow[t]{3}{*}{1.} & I & Pagi & 87,4 & \\
\hline & & Siang & 92,17 & 89,37 \\
\hline & & Malam & 88,91 & \\
\hline \multirow[t]{3}{*}{2.} & II & Pagi & 91,41 & \\
\hline & & Siang & 74,76 & 80,51 \\
\hline & & Malam & 76,12 & \\
\hline \multirow[t]{3}{*}{3.} & III & Pagi & 91,67 & \\
\hline & & Siang & 77,50 & 83,73 \\
\hline & & Malam & 82 & \\
\hline
\end{tabular}

Perbedaan kadar BOD sebelum diolah dan sesudah dapat dilihat dari hasil uji statistik Paired T-Test yang dilakukan dengan bantuan program SPSS pada Tabel 5 sebagai berikut :

Tabel 5. Hasil Uji Statistik Paired T-Test

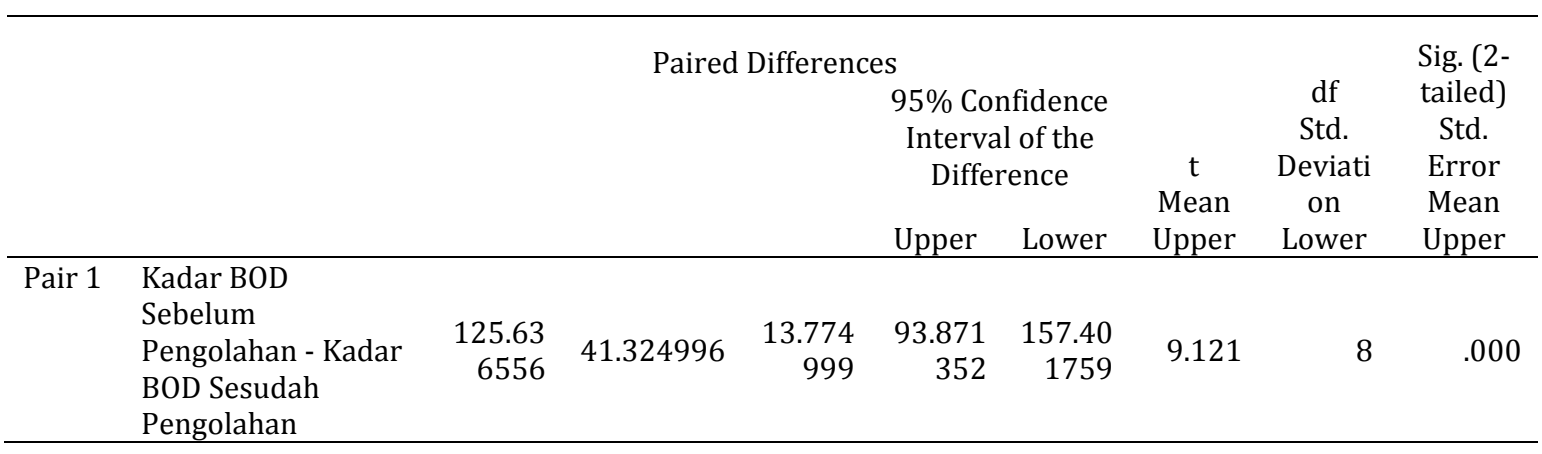


Sistem RBC relatif sensitif terhadap perubahan suhu. Suhu optimal untuk proses RBC berkisar antara $15-40{ }^{\circ} \mathrm{C}$ [4]. Dari tabel 1 pada hasil pengukuran suhu sebelum menunjukan hasil rata-rata $28,7^{0}$ C dan sesudah pengolahan menujukan hasil rata-rata $27,6^{0} \mathrm{C}$. dari hasil tersebut menujukan bahwa suhu sebelum dan sesudah pengolahan masih dalam kisaran optimal untuk proses pengolahan air limbah dengan RBC. Jika nilai suhu dibawah atau diatas padakisaran tersebut maka akan mempengaruhi microorganisme yang ada dalam bak pengolahan.

Dari tabel 2 pada hasil pengukuran $\mathrm{pH}$ menjukan sebelum dilakukan pengolahan dengan rata-rata 6 dan sesudah dilakukan pengolahan 6,5. Hasil tersebut masih dalam standar bakumutu PERGUB Kalimantan Selatan No.4 Tahun 2007 Tentang Bakumutu Limbah Cair.

Dari tabel hasil 4 diketahunya ratarata persentase pengolahan pada hari pertama sebesar 83,97\%, hari kedua sebesar 80,51 \%, dan hari ketiga sebesar $83,73 \%$. Persentase penurunan kadar BOD dalam air limbah sebelum dan sesudah pengolahan dengan sistenm RBC sudah sangat baik dikarnakan hasil ratarata persentase penurunankadar BOD diatas $80 \%$. Hasil tersebut menunjukan sistem RBC yang ada di IPAL Pekapuran Raya PD PAL Kota Banjarmasin sudah Efektif dalam menurunkan kadarBOD limbah cair domestik. Efektifnya sistem RBC terhadap penurunan kadar BOD limbah cair domestik dipengaruhi oleh lama waktu kontak.

Dari hasil tabel 5 diketahuinya ada perbedaan antara kadar BOD sebelum dan Sesudah diolah menggunakan sistem RBC pada IPAL Pekapuran Raya PD PAL Kota Banjarmasin. Hasil tersebut dapat dibuktikan berdasarkan uji statitistik Paired T-Test dimana pada kolom sig $0,000<\alpha(0,05)$ yang berararti ada perbedaan kadar BOD sebelum dan sesudah pengolahan dengan sistem RBC pada IPAL Pekapuran Raya PD PAL kota Banjarmasin.

\section{KESIMPULAN DAN SARAN}

Berdasarkan hasil penelitian untuk mengetahui efektivitas sistem RBC pada PD.PAL Banjarmasin terhadap penurunan kadar BOD (Biological Oxygen Demand), dapat mengambil kesimpulan nilai suhu dan pH pada sampel air limbah sebelum diolah dan sesudah diolah dengan sistem RBC pada IPAL Pekapuran Raya PD PAL Banjarmasin untuk suhu adalah sebelum dilakukan pengolahan rata-rata $28,7^{0} \mathrm{C}$ dan sesudah dilakukan pengolahan ratarata $27,6^{\circ} \mathrm{C}$.

Untuk pH sebelum dilakukan pengolahan rata-rata 6 dan sesudah dilakukan pengolahan rata-rata 6,5 . Efektifitas RBC terhadap penurunan kadar BOD (Biological Oxygen Demand) pada IPAL Pekapuran Raya PD PAL kota Banjarmasin adalah dengan rata-rata 84,53\%.Terdapat perbedaan kadar BOD (Biological Oxygen Demand) sebelum dan sesudah diolah dengan RBC pada IPAL Pekapuran Raya PD PAL kota Banjarmasin.

\section{KEPUSTAKAAN}

1. Haryoto, K. 1999. Kebijakan dan Strategi Pengolahan Limbah dalam Menghadapi Tantangan Global. Di dalam : Teknologi Pengolahan Limbah dan Pemulihan Kerusakan Lingkungan. Prosiding Seminar Nasional, Jakarta 13 Juli 1999, BPPT, Jakarta.

2. Angga Dheta SA. 2007. Pengaruh Lama Waktu Aerasi Terhadap Penurunan Kadar Amoniak, Nitrit, Nitrat Senyawa Organik, dan Zat Padat Air Limbah Domestik pada Bak Aerasi Prototipe IPAL Sistem Lumpur Aktif. Skripsi.UM. Malang.

3. Said, N. I. (2008). Pengolahan Air Limbah Domestik Di DKI Jakarta. Jakarta: Pusat Teknologi Lingkungan.

4. Banjarmasin, P. P. (2016). Laporan Kualitas Air Bulan November. Banjarmasin: PD.PAL. 
518 Jurnal Kesehatan Lingkungan Vol. 14 No. 2, Juli 2017 